\title{
An Empirical Analysis of the Effect of Education on Birth Rate Based on Chinese Provincial Panel Data
}

\author{
Tianjiao Qi \\ School of Sichuan University, Chengdu 610000, China \\ qtj98777@163.com
}

\begin{abstract}
China's birthrate is moving towards a dangerously low level. Based on the provincial panel data from the 2013-2017 China Statistical Yearbook and the population survey, through an empirical model, this paper analyzed the impact of education on the birthrate of a province and found that the illiteracy rate has a positive effect on the birthrate of a province; while the quality of basic education has a negative effect on it; there is no significant evidence that the proportion of higher-educated women in a province will affect its fertility. Finally, we put forward three suggestions for improving fertility level, optimizing population structure and enriching high-quality labor.
\end{abstract}

Keywords: Birthrate, Education, Fertility plan.

\section{Introduction}

In recent years, more and more countries and regions have gradually moved on to the stage of low-level birth rate, and the overall birth rate has shown a significant declining trend. In 2013, the overall fertility rate in China was $12.8 \%$. After the universal two-child policy in 2016, the fertility rate has increased slightly but has fallen significantly since 2017 . The proportion of the population aged 65 and over in total in China has already exceeded 9\% since 2013 and continuously increased. It is generally believed that a country is suffering the aging of population when this indicator is more than $7 \%$, which will cause social issues such as economic downturn and disappearance of the demographic dividend, etc. It is impossible to solve the problem of "low fertility trap" simply relying on the family policy. Therefore, finding other factors affecting fertility behavior is crucial.

\section{Literature References}

In 1960s, Becker studied fertility behavior using the indifference curve and proposed the concept of "trade-off between quality and quantity". Becker also argued that rising opportunity costs for fertility and upbringing will lead to a decline in birthrate, such as education and cultural levels [1].

Some scholars who support Becker (Wusu, Shapiro) [2,3] have proved through empirical evidence that the promotion in women's education will increase the opportunity cost of raising children, and this is the main reason for the decline in fertility. Freedman also pointed out that women with higher social status and education level will make it easier to take measures to restrain fertility when they participate in social activities. The fertility level of such society is often low [4]. Moreover, there are still many scholars at the micro level to explore the impact of fertility on women's income, education level and age gap between husband and wife. [5,6]

However, not all studies have concluded that the promotion in factors such as education has a significant negative effect on fertility. Zhou Jingxiang (2014) [7] found that the higher education level, the greater the probability of giving birth to a child, since the time of education delays marriage and childbirth, while the higher education level will change the fertility desire and make the necessary adjustments. Chen Zhonghan and Wu Ruijun (2009) [6] also found that the high-income earners in developed regions have higher fertility willingness through field surveys in Minhang District, Shanghai. Therefore, there is no significant evidence for the statement that "the fertility declines as education level increases".

In the existing research, based on China's provincial data, the research on the impact of education level on birth rate is not perfect. Therefore, from the perspective of education in a province, this paper 
will study the overall impact of these factors on fertility levels by refining the education level of a province into the illiteracy rate, the quality of basic education and the higher education of Women.

\section{Empirical Analysis}

\subsection{Data Source}

Due to the data availability, we collected the annual panel data of 31 provinces (excluding Taiwan, Hong Kong, and Macao) in a five-year period from 2013 to 2017, according to the national 1\% population sample survey in 2015, and 1\%o population sample survey in other years. The sampling survey is based on the whole country, and the provincial units are the sub-populations.

\subsection{Variable Selection}

In this paper, the dependent variable is the birth rate of each province, and the independent variables are the illiteracy rate, the quality of basic education, and the proportion of women in higher education in each province, the household consumption level in each province and the birth policy are the control variables.

\subsubsection{Birth Rate (BR)}

Birth rate refers to the ratio of the number of births in a certain area within a certain period of time (in a year) to the average number of people in the same period, expressed in thousands of points. In this paper, it refers to the birth rate in a province.

\subsubsection{Illiteracy Rate (ILR)}

The statistics of the proportion of illiterate people in the provinces aged 15 and over are selected.

\subsubsection{Female in Higher Education (FHE)}

Due to the different population bases in different provinces, it is more reasonable to indicate the overall degree by the ratio of the number of women in higher education to the total number of higher educations in the province. Higher education refers to tertiary and higher level.

\subsubsection{Quality of Basic Education (QBE)}

The quality of basic education in the province is represented by the ratio of high school teachers and students in each province.

\subsubsection{Household Consumption Level(HCL)}

Previously, many studies have shown that the level of economic development and the quality of life are both important factors affecting the fertility rate in the region. After analysis, there is a serious collinearity problem between the per capita GDP and the household consumption level. Therefore, this paper only sets the household consumption level as the control variable and reflects the residents' quality of life in a province.

\subsubsection{Fertility Policy(FP)}

This paper uses family planning policy to measure the impact of the birth policy on the fertility. In 2013, China relaxed its birth policy and initiated the "selective teo-child policy". And then the "universal two-child policy" was fully released from January 1, 2016. The policy variable is set to a dummy variable. Specifically, the value is 0 in 2013-2015, and the value is 1 in 2016-2017.

\subsection{Model Design}

Due to the influence of heteroscedasticity of data, all independent variables are taken as natural logarithms to overcome it, to obtain effective and consistent parameter estimates. Based on the previous studies, this paper sets the model to:

$$
B R i t=\alpha i+\beta 1 * \ln (\text { ILRit })+\beta 2 * \ln (F H E i t)+\beta 3 * \ln (Q B E i t)+\beta 4 * \ln (H C L i t)+\beta 5(F P O)+\varepsilon i t
$$


Where $\alpha \mathrm{i}$ is the individual difference fixed effect model in the panel data determined by Hausman test, which does not change with time.

\subsection{Correlation Test}

According to the table below, the illiteracy rate, the quality of basic education, and the household consumption level are related to the birthrate at a significant level of $1 \%$, and the correlation coefficients are $0.57,-0.63,-0.41$, respectively. All of them are closely related to the birth rate, and the illiteracy rate is positively correlated with the birthrate whereas the quality of basic education has a negative correlation with birthrate. However, the regression coefficient of the policy is 0.095 , which is significant at the level of $1 \%$, while $\ln (\mathrm{HCL})$ does not reflect the trend that the fertility rate will decrease significantly as the figure increases.

Table 1. Correlation Test

\begin{tabular}{|c|c|c|c|c|c|c|}
\hline & Ln (BR) & Ln (ILR) & Policy & Ln (FHE) & Ln (QBE) & Ln (HCL) \\
\hline $\operatorname{Ln}(\mathrm{BR})$ & 1.00 & & & & & \\
\hline Ln (ILR) & $0.57 * * *$ & 1.00 & & & & \\
\hline Policy & 0.09 & -0.02 & 1.00 & & & \\
\hline Ln (FHE) & -0.13 & 0.04 & 0.12 & 1.00 & & \\
\hline $\operatorname{Ln}(\mathrm{QBE})$ & $-0.63 * * *$ & $-0.47 * * *$ & 0.07 & $0.16^{* *}$ & 1.00 & \\
\hline Ln (HCL) & $-0.41 * * *$ & $-0.52 * * *$ & $0.29 * * *$ & -0.01 & $0.42 * * *$ & 1.00 \\
\hline
\end{tabular}

\subsection{Regression Analysis}

To overcome the heteroscedasticity between groups, regression analysis was performed using generalized least squares. The regression results are as follows:

Table 2. Regression Results

\begin{tabular}{|c|c|c|c|c|c|c|}
\hline \multicolumn{7}{|c|}{ 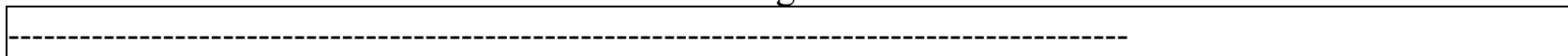 } \\
\hline $\operatorname{Ln}(\mathrm{BR})$ & Coef. & Std. Err. & z & $\mathrm{P}>|\mathrm{z}|$ & \multicolumn{2}{|c|}{ [95\% Conf. Interval] } \\
\hline \multicolumn{7}{|c|}{ 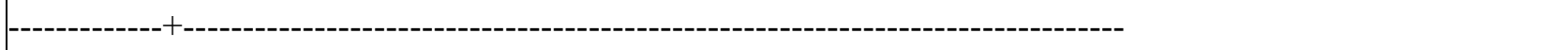 } \\
\hline Ln (ILR) & .1340974 & .0289815 & 4.63 & 0.000 & .0772947 & .1909001 \\
\hline $\operatorname{Ln}(\mathrm{QBE})$ & -.7217141 & .1105023 & -6.53 & 0.000 & -.9382946 & -.5051336 \\
\hline Ln (FHE) & -.2623609 & .1627213 & -1.61 & 0.107 & -.5812888 & .0565671 \\
\hline Policy & .0946954 & .0326712 & 2.90 & 0.004 & .0306609 & .1587298 \\
\hline $\operatorname{Ln}(\mathrm{HCL})$ & -.0753507 & .0475994 & -1.58 & 0.113 & -.1686439 & .0179424 \\
\hline cons & 5.442969 & .7825702 & 6.96 & 0.000 & 3.90916 & 6.976779 \\
\hline
\end{tabular}

The regression coefficients of $\ln$ (ILR) and $\ln (\mathrm{QBE})$ are 0.134 and -0.722 , respectively. Both are significant at the $1 \%$ confidence interval. The increase of illiteracy rate will lead to a significant increase in fertility, but the promotion of quality of basic education will cause a significant decline in provincial birthrate given the same condition. However, ln (FHE) is not significant at the 10\% confidence level, that is, the degree of women's higher education fails to show a significant reduction in fertility. In addition, the regression coefficient of the policy is 0.095 , which is significant at the level of $1 \%$, while $\ln (\mathrm{HCL})$ does not reflect the trend that the fertility rate will decrease significantly as it increases. 


\section{Conclusion}

Through the analysis of the above provincial panel data, the following conclusions are drawn:

First, the provincial illiteracy rate has a significant positive effect on the fertility rate of the province. It can be seen that the education level of each province affects its birth rate. When people especially women are poor in education with lower social status, they are unable to participate in social activities, therefore the birthrate will often increase. However, the increase in birthrate due to the illiteracy rate cannot effectively guarantee the quality of life of the next generation, nor can it guarantee the provision of high-quality and effective labor for the society. To some extent, population growth caused by low-level education may even hinder social development.

Secondly, the quality of basic education in each province has a significant negative effect on the fertility rate, that is, the improvement of the quality of basic education in a province will reduce its birthrate. On the one hand, people pay more attention to the quality of children rather than quantity in the provinces with high quality of basic education; on the other hand, due to this, the education level of their children will increased, as well as the opportunity cost of childbearing, so that people change their fertility decision.

Third, according to the analysis of China's provincial panel data, there is no obvious relationship between the proportion of women in higher education and the birthrate in a province. It cannot be concluded that the increase in the level of female education will lead to an increase or a decrease in fertility rate at the macro level. As also mentioned above, the question of how the level of female higher education acts on fertility needs to be further studied.

Fourth, China's two-child policy has brought about a significant promotion in fertility, but the impact has a marginal decline, which means that China needs to take other steps to improve this problem.

\section{Suggestion}

In China, the current low fertility rate has been changed from policy, compulsory, exogenous to cultural, voluntary and endogenous. Apart from the fertility policy, the government should take other measures to improve people's desire to give birth and ensure the quality of the next generation:

First, government should adjust macroeconomic policies dynamically based on the reality and the trend of future development in order to meet the situation of society and promote the long-term balanced development of the population.

Second, government also needs to further improve basic education facilities. With the changes in the fertility policy, demand for education is constantly changing. The government should investment more in education and culture life, more faculty and schools are needed to ensure the quality of basic education as well, thus optimizing the population structure and providing more effective workforce.

Third, creating a social atmosphere of "work-family-friendly" [9] is necessary. government can learn from the other countries to further improve employment, social security system and related infrastructure. Flexible working hours system, women's maternity subsidies and reemployment subsidies can release the dual pressures of women from both family and society and reduce the cost of birth, thus further enable more family to achieve "voluntary fertility".

\section{References}

[1]. Becker G S an economic analysis of fertility, demographic and economic change in developed countries, New York: Columbia university press 1960, pp. 209-240.

[2]. Wusu, O. (2012), "a reassessment of the effects of female education and employment on fertility in Nigeria", Vienna Yearbook of Population Research 10(1):31-48.

[3]. Shapiro, D. (2012), "women's education and fertility transition in sub-Saharan Africa”, Vienna Yearbook of Population Research 10:9-30. 
[4]. Freedman R. Theories of fertility decline: A Reappraisal[J]. Social Forces,1979,58(1):1-17.

[5]. Schultz T P. An economic Model of Family Planning and Fertility [J]. Journal of Political Economy. 1969,77(2):153-180.

[6]. Kalwij A S. The effects of female employment status on the presence and number of children [J]. Journal of Population Economics, 2000,13(2):221-239.

[7]. Zhou Jingxiang, 2014: Research on the Decision of Chinese Women's Fertility Desire: Based on the Perspective of Income from Salary Income, Journal of Labor Economics, No.1.

[8]. Chen Zhonghan Wu Ruijun, 2009; "Higher Fertility Intention in Higher Income Groups in Cities and Theoretical Interpretation"; Northwest Population" No.6.

[9]. Wu Fan, "European Family Policy and Fertility Change_-Also on the Risk of China's Low Fertility Trap", Sociological Research, No. 1, 2016.

[10]. Li Zilian, "Revenue and Fertility: An Explanation of Changes in China's Fertility Rate", Economics Dynamics, No. 5, 2016. 